\title{
Role of Computed Tomography Guided Fine-Needle Aspiration Cytology in the Study of Various Thoracic Mass Lesions
}

\author{
Nawanita Kumari¹, Nidhish Kumar², Sharvani Singh³ ${ }^{3}$ Vishal Vaibhaw ${ }^{4}$ \\ ${ }^{1}$ Department of Transfusion Medicine, AIIMS, Patna, Bihar, India. ${ }^{2}$ Department of Pathology, IGIMS, \\ Patna, Bihar, India. ${ }^{3}$ Prakash Pathology and Radiology Pvt ltd, Varanasi, Uttar Pradesh, India. \\ ${ }^{4}$ Department of Anaesthesia, Patna Medical College and Hospital, Patna, Bihar, India.
}

\section{ABSTRACT}

\section{BACKGROUND}

Intrathoracic mass is a problem faced by the clinicians worldwide which is difficult to diagnose correctly. The mediastinum although a small anatomic compartment, the pathologic processes found in it are diverse. Imaging techniques are very helpful for detection and diagnosing these lesions. The current study was conducted for assessing the diagnostic accuracy and efficacy of computed tomography (CT) guided fine-needle aspiration cytology (FNAC) in the evaluation of various thoracic mass lesions and also to compare the histopathological findings of CT guided FNAC for evaluation of the type of thoracic lesions \& its prognosis.

\section{METHODS}

Data for the study was collected from 50 patients referred to the Department of Pathology, in a tertiary care hospital for 16 months from December 2015 to March 2017.

\section{RESULTS}

Among 50 patients with intrathoracic mass, there were 37 men (74 \%) and 13 women (26\%). The age of patients with intrathoracic masses in this study varied from 31 to 80 years. The mean age was 55 years. Thirty-two patients were found to have malignant tumours and 18 cases were of benign aetiology. The highest frequency of cases in this study were of adenocarcinoma followed by squamous cell carcinoma.

\section{CONCLUSIONS}

Computed tomography (CT) guided fine-needle aspiration cytology (FNAC) is a cost effective, simple, safe, highly sensitive \& specific procedure with high diagnostic accuracy in the diagnosis of intrathoracic mass lesions. It has few complications, rarely requiring active management.

\section{KEY WORDS}

Intrathoracic Mass, Fine-Needle Aspiration Cytology, Pneumothorax, Pneumonectomy, Thoracic Mass Lesions
Corresponding Author: Dr. Nidhish Kumar, C/O Dr. Mohan Singh, Jagat Narayan Road, Kadam Kuan, Patna-800003.

Bihar, India.

E-mail: drnidhishkumar@gmail.com

DOI: $10.14260 /$ jemds/2021/269

How to Cite This Article:

Kumari N, Kumar N, Singh S, et al. Role of computed tomography guided fine-needle aspiration cytology in the study of various thoracic mass lesions. J Evolution Med Dent Sci 2021;10(18):1269-1274, DOI: 10.14260/jemds/2021/269

Submission 03-08-2020, Peer Review 28-02-2021, Acceptance 06-03-2021, Published 03-05-2021.

Copyright (C) 2021 Nawanita Kumari et al. This is an open access article distributed under Creative Commons Attribution License [Attribution 4.0 International (CC BY 4.0)] 


\section{BACKGROUND}

Intrathoracic mass is a problem faced by clinicians worldwide, which is difficult to diagnose correctly. Many methods and procedures including various techniques \& procedures are being used for diagnosing intrathoracic masses by deriving adequate tissue samples. ${ }^{1}$ The mediastinum is although a small anatomic compartment, the diversity of pathologic processes are profound that may be found in it. 2,3 With vast spectrum of pathological lesions in the intrathoracic cavity, it is a challenging task to diagnose these lesions, especially those which are deep seated, mediastinal and hilar regions, with high accuracy, safety and minimal morbidity to patients. ${ }^{4}$ Imaging techniques are very helpful in detecting and diagnosing these lesions. Except for few cases, it would not be wise to do thoracotomy for diagnosis of intrathoracic lesions and there are many hazards associated with thoracotomy. Thoracotomy is contraindicated for small cell anaplastic carcinoma, metastatic tumours and infections. A confident diagnosis of benign lesions such as tuberculosis / chondroid hamartoma helps avoiding unnecessary surgical intervention.

Percutaneous transthoracic fine-needle aspiration cytology (FNAC) was first used about 100 years ago. ${ }^{5}$ Muntrie in 1886 used the FNAC technique for the first time to diagnose lung cancer but the procedure was established in 1963 by Nordenstrom. ${ }^{6}$ FNAC is a procedure of involving adequate sampling and studying the cell smears obtained by the procedure. It is an easier and very minimal traumatic technique when compared to excision biopsy. It is widely used in cytological diagnosis with an excellent diagnostic accuracy.7,8 FNAC of deep-seated organs can be done with the help of ultrasonography (USG) or computed tomography which can be used as a guidance.9,10,11 Ultrasound guided FNAC are used in diagnosis of lung masses which are peripheral. Intrathoracic masses which are deep may not be seen by USG. ${ }^{12,13,14}$ CT visualisation and guidance allows FNAC of nearly all lesions or masses which can be seen with CT scan. The masses can be of any size or position. ${ }^{15}$ Various types of lung malignancies can be diagnosed with confidence and accuracy and their cytomorphological characterisation can be done in right context. ${ }^{16}$ The type of bronchogenic carcinoma can be subclassified with accuracy and ease. It can also suggest the most probable primary site of tumours in metastatic lung tumours.

The regions which contain viable tumour cells can be easily differentiated in contrast enhancement from the lowdensity centre containing normal tissue. An extra-pleural approach can also be done to mediastinal lesions. This is very important in patients with small-size lesions, whose clinical conditions can result in pneumothorax, which is life threatening. ${ }^{17}$ CT guided FNAC (transthoracic) can also be performed easily as an outdoor procedure very safely. Various researchers have suggested CT guided (transthoracic) FNAC as the primary and $1^{\text {st }}$ method to diagnose intrathoracic masses which are deep. ${ }^{16}$ FNAC by guided fluoroscopy of central lung masses are accepted and recognised as a diagnostic method but are not practiced everywhere routinely. On the other hand, CT scan is available and performed in various centres. It is available in most of the districts in our country.

With CT guidance it is very easy to do a biopsy on various portions of chest with high degree of safety with minimal morbidity because of ability to plan a needle path such that the major blood vessels are avoided. It has now slowly become the first line diagnostic procedure which is frequently used in diagnosing lung malignancies and confirming metastasis. It is also especially helpful in diagnosing mediastinal and hilar masses where major great vessels are present, and the masses are deep seated in position. The accuracy of diagnosis and the sensitivity of CT guided FNAC in malignant tumours ranges from $64 \%$ to $97 \%$ \& $76 \%$ to $97 \% .{ }^{18,19,20}$ This aids clinician to implement appropriate anticancer treatments like chemotherapy and radiotherapy. Pneumothorax, haemorrhage, chest pain and haemoptysis are the most common side effects and complications of this technique with some patients requiring a prompt management. But these post procedure complications are fewer $\&$ seen in small percentage of cases. The risk to develop pneumothorax has been observed in $22 \%-45 \%$ due to high accuracy and sensitivity of CT in detecting pneumothorax. ${ }^{21}$ Most important contraindications to image guided FNAC are bleeding diathesis, severe chronic obstructive airway disease, contralateral pneumonectomy \& pulmonary arterial hypertension. ${ }^{22}$ Limited Indian studies are available regarding the diagnostic yield \& safety profile of this procedure. ${ }^{23,24,25}$ This study was done to evaluate the type of tumour \& its prognosis using CT guided FNAC as diagnostic tool. Even though sensitivity and specificity of CT guided FANC \& biopsy is very high histology and immunohistochemistry serves as a gold standard for definitive diagnosis. This study was conducted to assess and see the diagnostic accuracy, compare the histopathological findings \& utility of CT guided FNAC in evaluation of various thoracic mass lesions with comparison of cytomorphological features.

\section{METHODS}

This is a case-control study. Data for the study was collected from 50 patients referred to the Department of Pathology, in a tertiary care hospital for 16 months from December 2015 to March 2017. The total number of cases for intrathoracic masses which passed the inclusion criteria who presented at the hospital were included in the study. Cooperative patients who were able to hold breathe for a short while with no bleeding tendency or coagulopathy were included in the study.

\section{Exclusion Criteria}

Patients having severe chronic obstructive pulmonary disease forced expiratory volume (FEV1 < $30 \%$ predicted / respiratory failure), pulmonary arterial hypertension, bleeding disorders (which included drug-induced bleeding tendency) and contralateral pneumonectomy were excluded.

\section{Procedure}

Investigations done before the procedure were bleeding time (BT), clotting time (CT) and platelet count \& oxygen saturation. Past plain and contrast CT of chest which is recent is made available prior to CT guided FNAC. All scans were done using fourth generation spiral CT scanner GE bright speed elect (16 slice) with $120 \mathrm{KVp}$ and $300 \mathrm{mAs}$. The risks and benefits arising from the procedure were explained and after that FNAC procedure was done. A written consent was taken from each patient. From the area of interest an axial scan was 
done to see and localise the tumour. The probable approximate distance from the surface, tumour \& needle angulation was calculated. The probable approach which was best (supine or prone or lateral) for the lesion was calculated and judged. A marker was used to mark the site of skin puncture. The marker was radiopaque. The puncture site was cleaned and then draped and a local anaesthetic (2\% xylocaine) was pushed and infiltrated at the puncture site. The infiltration was deep into the pleura. A 22-gauge spinal needle was used and inserted when the respiration was suspended. The tip of the needle was directed towards the lesion. The needle was slowly pushed towards the lesion \& when the tip of the needle reached into the lesion, a repeat slice was taken to reconfirm the desirable area from where the biopsy was to be taken. The stylet was then withdrawn and removed. The needle was advanced 2 to $3 \mathrm{~cm}$ into the mass lesion. A rotating motion with the needle was performed during suspended respiration, so that the tip resides within the lesion to be targeted. After removal of stylet, a 10-ml syringe was attached and the plunger was pulled back with continued hard suction. Needle was jiggled which helped in freeing material from the tumour to the needle's lumen. Multiple smears were prepared immediately from the sample. Usually two slides were kept as dried specimens and three to four slides were fixed immediately in $95 \%$ alcohol. Air-dried smears were made and stained with May-Grunwald-Giemsa (MGG) stain and alcoholfixed smears were stained with Papanicolaou (Pap) and haematoxylin and eosin (H \& E) stains for rapid cytopathological evaluation of the lesion. A follow-up CT scan was done in all the patients immediately after the procedure which ruled out complications like pneumothorax. In cases where the aspirate material was unsatisfactory, a repeat procedure was done. An expiratory chest film was done in upright position in all patients after one hour to rule out postFNAC complications like pneumothorax. The patient was kept under observation for 24 hours. In cases of pneumothorax a chest $\mathrm{x}$-ray of posteroanterior (PA) view was done after 24 hours to rule out any other complications. In the cases with no complications, the patients were discharged. All the patients were observed and followed up from the time of performing procedure to the final diagnosis. Final diagnosis was made by examining surgical specimens grossly and even biopsy from Tru-cut needle or by bronchoscope. Therapeutic response with evaluation and similar diagnosis made at other sites in the body with clinical correlation and follow up in case of metastatic lesions. A comparison between cytological diagnosis and final diagnosis was done and evaluated.

\section{Statistical Analysis}

Statistical analysis was performed to observe the diagnostic value of CT guided FNAC in the diagnosis of sonographically non-approachable intrathoracic masses. This was done by calculating sensitivity, specificity, accuracy, positive and negative predictive value for malignant and benign lesions. Data was analysed by graphs, tables and proportions. Various morphological features were studied and eventually analysed in order of their frequency. They were compared with each other and the final diagnosis was done using chi-square value and Fischer's test. P-value which was of less than 0.05 was considered to be significant statistically.

\section{RESULTS}

In 50 patients with intrathoracic masses, 37 were men (74 \%) and 13 women (26\%). The age distribution of patients in intrathoracic masses in this study was between the age range of 31 - 80 yrs. The mean age being 55 years. $24 \%$ were in the age range of 31 - 50 years $(\mathrm{N}=12), 60 \%$ were in the age range of $51-70$ years $(\mathrm{N}=30)$ and $16 \%$ were in the age range of 71 - 80 years $(\mathrm{N}=8)$. It was observed that intrathoracic mass lesions were more common in the age group of $51-70$ years. Lungs being the most common site of the mass (68\%). Other most common sites were hilum (14\%) \& mediastinal (18\%).

Adenocarcinoma was the most common carcinoma accounting for $30 \%$ of cases followed by squamous cell carcinoma (16\%), small cell carcinoma (6\%), large cell carcinoma (4\%), metastatic carcinoma (6\%), benign lesions (34\%) and undiagnosed were $4 \%$ of cases. Cough was present in $70 \%$ of patients, followed by weight loss in (58\%), loss of appetite in (58\%), dyspnoea in (28\%), haemoptysis in (20\%), chest pain in (24\%), fever in (10\%) and $6 \%$ of patients were asymptomatic. Total count was increased in $34 \%$ of cases, erythrocyte sedimentation rate (ESR) in $48 \%$, and chest x-ray showed lesions in $100 \%$ of cases.

\begin{tabular}{|c|c|c|c|c|c|c|}
\hline & \multicolumn{2}{|c|}{ Absent } & \multicolumn{2}{|c|}{ Present } & \multicolumn{2}{|c|}{ Total } \\
\hline & $\begin{array}{c}\text { No. of } \\
\text { Patients }\end{array}$ & $\%$ & $\begin{array}{c}\text { No. of } \\
\text { Patients }\end{array}$ & $\%$ & $\begin{array}{c}\text { No. of } \\
\text { Patients }\end{array}$ & $\%$ \\
\hline Hilar & 39 & 78.0 & 11 & 22.0 & 50 & 100.0 \\
\hline Peribronchial & 49 & 98.0 & 1 & 2.0 & 50 & 100.0 \\
\hline Mediastinal & 6 & 12.0 & 44 & 88.0 & 50 & 100.0 \\
\hline Subcarinal & 33 & 66.0 & 17 & 31.0 & 50 & 100.0 \\
\hline Supraclavicular & 46 & 92.0 & 4 & 8.0 & 50 & 100.0 \\
\hline \multicolumn{7}{|c|}{ Table 1. Lymphadenopathy Distribution } \\
\hline
\end{tabular}

Thirty-two patients were diagnosed with malignant lesions and 18 cases were diagnosed with benign lesions. The highest number of cases being adenocarcinoma followed by squamous cell carcinoma.

\section{Comparison between Squamous Cell Carcinoma and Adenocarcinoma}

Seventy percent of patients with central lesions had squamous cell carcinoma ( $\mathrm{N}=7$ ) and $30 \%$ had adenocarcinoma $(\mathrm{N}=3)$. Eighty percent of cases with peripheral mass lesions had adenocarcinoma $(\mathrm{N}=12)$ and $20 \%$ of cases had squamous cell carcinoma $(\mathrm{N}=1)$. Chi-square value $=8.968, \mathrm{P}=0.003$, highly significant. Hence it was concluded that squamous cell carcinoma presented as central lesion predominantly and adenocarcinoma presented as a peripheral lesion.

\section{Gender Distribution in Squamous Cell Carcinoma and Adenocarcinoma}

Nearly $14.3 \%$ of female patients had squamous cell carcinoma $(\mathrm{N}=1)$ and $85.7 \%$ had adenocarcinoma $(\mathrm{N}=6)$. About 43.75 $\%$ of male patients had squamous cell carcinoma $(\mathrm{N}=7)$ and $56.25 \%$ had adenocarcinoma $(\mathrm{N}=9)$. Chi-square value -6.93 , $\mathrm{P}=0.008$, highly significant. From this study it was evident and it was seen that adenocarcinoma was most commonly seen in female gender and squamous cell carcinoma was most commonly seen in male gender. 
Relationship between Smoking, Squamous Cell Carcinoma and Adenocarcinoma

Among the non-smokers, $10 \%$ of cases were seen having squamous cell carcinoma $(\mathrm{N}=1)$. The remaining $90 \%$ were seen having adenocarcinoma $(\mathrm{N}=9)$. In smokers, $53.85 \%$ were seen having squamous cell carcinoma $(\mathrm{N}=7)$ and 46.15 $\%$ were seen having adenocarcinoma $(\mathrm{N}=4)$. Chi-square value $-24.88, \mathrm{P}=0.001$, which was found to be highly Significant. Thus, it was inferred that adenocarcinoma most commonly affects non-smokers and squamous cell carcinoma was most commonly seen in smokers.

\begin{tabular}{|c|c|c|c|c|c|}
\hline & Sensitivity & Specificity & Accuracy & $\begin{array}{c}\text { Positive } \\
\text { Predictive } \\
\text { Value }\end{array}$ & $\begin{array}{c}\text { Negative } \\
\text { Predictive } \\
\text { Value }\end{array}$ \\
\hline $\begin{array}{c}\text { Malignant } \\
\text { intrathoracic } \\
\text { masses }\end{array}$ & c $93.85 \%$ & $99 \%$ & $96 \%$ & $99 \%$ & $89.74 \%$ \\
\hline $\begin{array}{c}\text { Benign } \\
\text { intrathoracic } \\
\text { masses }\end{array}$ & c $94.29 \%$ & $98.29 \%$ & $97 \%$ & $97.06 \%$ & $96.97 \%$ \\
\hline $\begin{array}{r}\text { Table } 2 \\
\text { Nega }\end{array}$ & $\begin{array}{l}\text { Depicting } \\
\text { ive Predi }\end{array}$ & $\begin{array}{l}\text { nsitivity, } \\
\text { e Value c }\end{array}$ & $\begin{array}{l}\text { cificity, } \\
\text { alignan }\end{array}$ & $\begin{array}{l}\text { curacy, P } \\
\text { nd Benign }\end{array}$ & $\begin{array}{l}\text { itive and } \\
\text { Masses }\end{array}$ \\
\hline
\end{tabular}

The sensitivity, specificity, accuracy, positive predictive value and negative predictive value of CT guided FNAC of transthoracic mass lesions were $93.85 \%, 99 \%, 96 \%, 99 \%$ \& $89.74 \%$ respectively in cases of malignant intrathoracic masses and $94.29 \%, 98.46 \%, 97 \%, 97.06 \%$ \& $96.97 \%$ respectively in cases of benign masses. CT guided FNAC proved out to be a very safe procedure. Out of 50 cases no complication was seen in $67 \%$ cases. Only 09 cases complained of pain at puncture site. Small amount of pneumothorax was seen in 05 cases. Single episode of haemoptysis was seen in just one case. However, treatment was not required in any of the cases where complications arose. They resolved by their own.

\section{DISCUSSION}

Intrathoracic mass lesions are common radiological findings that pose relatively frequent clinical problem. An early and an accurate diagnosis is of very much importance in starting the most specific \& suitable therapy in cases of malignant lesions. And also, for avoiding procedures which are not necessary for benign conditions. CT guided (transthoracic) FNAC is an accurate method for diagnosing intrathoracic lesions which can be benign or malignant. This technique is now useful not only for diagnosis and classification but also for investigation of prognostic and predictive biomarkers, and use of ancillary techniques by proper retrieval of aspirated materials. FNAC is a very simple, safe, reliable \& inexpensive method in early detection of lesions. FNAC has become a very acceptable, widely practiced rapid technique since it is minimally invasive and relatively pain free. FNAC is accurate and highly cost effective which can act as first line investigative technique for diagnosis of reactive hyperplasia, granulomatous disorders, inflammatory conditions and malignancies in various cases which require further investigation, clinical follow up and surgical intervention. The procedure is all the more valuable resource in poor economics like ours, because of its simplicity, low cost of operation \& early availability of results.

\section{Age Distribution}

Intrathoracic mass lesions are seen more commonly in the age group of $51-70 \mathrm{yrs}$. This is also in similarity with other studies which were done by Jagdish R et al. ${ }^{26}$ \& Karuna RK et al. ${ }^{27}$ The mean age in this study was 55 yrs. which was similar to a study done by Krishnamurthy et al.28 On the other hand, it was slightly lesser than the mean age as seen in the study done by CM Shetty. ${ }^{29}$

\section{Gender Distribution}

Out of 50 patients of intra-thoracic mass, there were 37 men (74\%) and 13 were women (26\%). Male to female ratio was 2.8:1 in our study which was similar to the study of Jagdish $\mathrm{R}$ et al. ${ }^{26}$ which was 8.2:1, Krishnamurthya et al. ${ }^{28}$ which was $3.5: 1$, Shetty $\mathrm{CM}^{29}$ which was $12.5: 1$ and Yousif 30 which showed 2.5:1.

\section{Smoking as a Causative Factor}

In our study, there was evidence of a strong association between the occurrence of smoking and squamous cell carcinoma. $81 \%$ of the smokers were found to have squamous cell carcinoma. Similar results were obtained in study by Krishnamurthy $\mathrm{A}^{28}$ and Arora VK et al. ${ }^{31}$ Our study showed that adenocarcinoma is commonly seen in non-smokers $(95$ $\%$ ). This is in agreement with the study by Dey A. ${ }^{32}$

\section{Clinical Presentation}

\begin{tabular}{|c|c|c|c|c|c|c|}
\hline & $\begin{array}{c}\text { Present } \\
\text { Study }\end{array}$ & $\begin{array}{c}\text { Jagdish R } \\
\text { et al. }{ }^{26}\end{array}$ & $\begin{array}{c}\text { Arora } \\
\text { VK }^{31}\end{array}$ & Yousif ${ }^{30}$ & $\begin{array}{c}\text { Quamrul } \\
\mathbf{M}^{33}\end{array}$ & $\begin{array}{c}\text { Shetty } \\
\text { CM }^{38}\end{array}$ \\
\hline Cough & $69.4 \%$ & $72.9 \%$ & $92 \%$ & $98.5 \%$ & $89.8 \%$ & $55.5 \%$ \\
\hline Fever & $10 \%$ & $58.1 \%$ & $22 \%$ & - & $44.1 \%$ & - \\
\hline Chest pain & $24 \%$ & $55 \%$ & $52 \%$ & $20.5 \%$ & $62.7 \%$ & $33 \%$ \\
\hline Dyspnoea & $28 \%$ & $50 \%$ & $40 \%$ & $48.2 \%$ & $39 \%$ & $43.2 \%$ \\
\hline Haemoptysis & $20 \%$ & $25 \%$ & $29 \%$ & $64.1 \%$ & $42.4 \%$ & - \\
\hline Loss of weight & $58 \%$ & $56 \%$ & $30 \%$ & - & $47.5 \%$ & - \\
\hline
\end{tabular}

\section{Laboratory Investigations}

In our study, ESR was not elevated in $52 \%$ of cases which is not in agreement with the study done by Qaumrul et al. ${ }^{33}$ whose study revealed that most of the patients with malignancy had an elevated ESR. All of our patients (100\%) revealed an abnormality in chest radiograph based on which CT guided FNAC was suggested for further evaluation. Similar observations were seen in study by Yousef ${ }^{28}$ and Qaumrul et al. ${ }^{33}$ Hence it can be said that chest radiograph is the simplest and most effective tool in the earliest diagnosis of intrathoracic mass lesions.

\section{Location of Lesion}

Different location of the lesions was as follows: pulmonary 34 (68 \%), mediastinal 9 (18\%) and hilar 7 (14 \%). Adenocarcinoma was the most common malignant tumour which was followed by squamous cell carcinoma, metastatic carcinoma \& small cell carcinoma. Findings of this study were similar to the findings of the study done by Mostafa. ${ }^{34}$ 


\section{Validity Parameters}

\begin{tabular}{|c|c|c|c|c|c|c|}
\hline 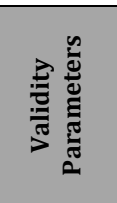 & 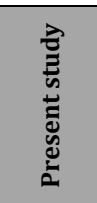 & 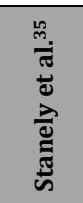 & 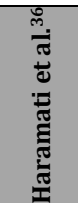 & 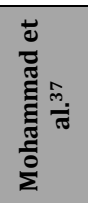 & 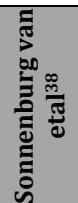 & 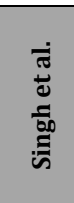 \\
\hline Sensitivity & $93.85 \%$ & $96.6 \%$ & $84 \%$ & $95.6 \%$ & $82.7 \%$ & $92.6 \%$ \\
\hline Specificity & $99 \%$ & $100 \%$ & $100 \%$ & $100 \%$ & $100 \%$ & $100 \%$ \\
\hline Accuracy & $96 \%$ & $96.6 \%$ & $81 \%$ & $97 \%$ & $81 \%$ & $85.3 \%$ \\
\hline PPV & $99 \%$ & $98.4 \%$ & $94.8 \%$ & & & $100 \%$ \\
\hline NPV & $89.74 \%$ & $90.5 \%$ & $93.7 \%$ & & & $75 \%$ \\
\hline \multicolumn{7}{|c|}{$\begin{array}{c}\text { Table } 4 \text { Present Study Validity Parameters } \\
\text { Compared with Previous Studies }\end{array}$} \\
\hline
\end{tabular}

CT guided (transthoracic) FNAC under diagnosed few intrathoracic masses in a very few cases, it did help in reaching up to accurate diagnosis in most of the cases.

\section{Complications}

Regarding the complications of CT guided FNAC, all the patients tolerated this procedure and method well with most commonly reported complication being pain at the puncture site which was observed in majority of cases. Puncture site pain was seen in 9 (18\%) cases which lasted for 3 - 6 hrs. which subsided automatically without medication. Pneumothorax as complication developed in only 5 (10\%) patients and single episode of scanty haemoptysis was seen in 1 (2\%) patient. All cases of pneumothorax were mild in nature. They showed mild complications which was seen within 10 minutes of the procedure. Chest tube insertion was required in no cases. No treatment was required in the cases of haemoptysis. Our study was similar to the study of Singh et al. where fatal complications were absent like endobronchial haemorrhage, tension pneumothorax, air embolism etc. The complication rate mostly depended on the distance of the lesion from pleura and the lesion size. The amount of lung tissue pierced by the needle was directly proportional to the complication rate and smaller the mass lesion more was the complication rate. In this study, needle of $22 \mathrm{G}$ size was used which caused minimal complications which correlated well with the study of Zavala et al. ${ }^{39,40}$

\section{CONCLUSIONS}

CT guided FNAC is a simple, safe, cost effective, highly sensitive \& specific procedure with high diagnostic accuracy for diagnosis of intrathoracic mass lesions. It has few complications, rarely requiring active management. The utility of FNAC in delineating various causes of intrathoracic mass lesions with cytomorphological features providing statistical data in documenting their demographic profile was established.

\section{Limitations}

Interobserver variation was noted in our study, as a single pathologist did not review all cases. Larger study population was needed for more precise results regarding diagnostic validity of this method.
Data sharing statement provided by the authors is available with the full text of this article at jemds.com.

Financial or other competing interests: None.

Disclosure forms provided by the authors are available with the full text of this article at jemds.com.

\section{REFERENCES}

[1] Singh MM, Gupta RK, Das DK, et al. Ultrasonically guided fine needle aspiration cytology (FNAC) of intrathoracic lesions. Indian J Chest Dis Allied Sci 1987;29(2):81-9.

[2] Wick MR, The Mediastinum. In: Mills SE, Carter D, Greenson JK, et al. eds. Strenberg's diagnostic surgical pathology. $5^{\text {th }}$ edn. Lippincott William \& Wilkins 2010: p. 1120-77.

[3] Dueñas VP, Sánchez IT, Río FG, et al. Usefulness CT-guided FNAC in the diagnosis of mediastinal lesions. Arch Bronconeumol 2010;46(5):223-9.

[4] David HH, David AL, McAdams HP, et al. Basic patterns in lung diseases. In: Imaging of diseases of the chest. $5^{\text {th }}$ edn. Mosby: Elsevier Ltd., 2010: p. 83-148.

[5] Menetrier P. Cancer primitive du poumon. Bull Soc Anat du Paris 1886:11:643.

[6] Nordenstrom B. A new technique for transthoracic biopsy of lung changes. Br J Radiol 1965;38(451):550-3.

[7] Kaur S, Kumar B, Gupta SK. Fine needle aspiration of lymph nodes in leprosy. A study of bactariologycal and morphological indices. Int J Lepr Other Mycobact Dis 1997;45(4):369-72.

[8] Gupta SK, Kumar B, Kaur S. Aspiration cytology of lymph nodes in leprosy. Int J Lepr 1981;49(1):9-15.

[9] Suen KC. Atlas and Textbook of Aspiration Biopsy Cytology. Baltimore: Williams \& Wilkins 1990: p. 1-15.

[10] Orell SR, Sterrett GF, Walters MN, et al. Manual and atlas of fine needle aspiration cytology. $2^{\text {nd }}$ edn. Edinburgh: Churchill Livingstone 1992: p. 172-216.

[11] Zornoza J, Wallace S, Ordonez N, et al. Fine needle aspiration cytology of the liver. AJR 1980;134:331-4.

[12] Rasmussen SN, Holm HH, Kristensen JK, et al. Ulrasonically-guided liver biopsy. $\mathrm{Br}$ Med J 1972;2(5812):500-2.

[13] Hancke S, Holm HH, Koch F. Ultrasound guided transthoracic fine needle aspiration biopsy of pancreas. Surg Gynecol Obstet 1975;140(3):361-4.

[14] Kristensen JK, Holm HH, Rasmussen SW, et al. Ultrasound guided transthoracicpuncture of renal masses. Scand J Urol Nephron 1972;(Suppl 15):47.

[15] Hagga JR. Image-guided microprocedures: CT and MRI interventional procedure. In: CT and MRI Imaging of the whole body. $4^{\text {th }}$ edn. St. Louis: Mosby 2003: p. 2123-2183.

[16] Gupta S, Wallace MJ, Morello AF, et al. CT-guided percutaneous needle biopsy of intrathoracic lesions by using the transsternal approach: experience in 37 patients. Radiology 2002;222(1):57-62.

[17] Gobien RP, Stanley JH, Vujic I, et al. Thoracic biopsy: CT guidance of thin-needle aspiration. AJR Am J Roentgenol 1992;142(4):827-30.

[18] Prashant, Ramachandra C, Pattbhiraman, et al. Feasibility, safety and efficacy of the CT guided fine needle aspiration. Indian J Med Pediatr Oncol 2007;28(2):16-24. 
[19] Mohammad GM. CT guided fine needle aspiration cytology in the diagnosis of thoracic lesions. JIMA 2001;99(10):1-5.

[20] Emara MM, El-Badrawy A, Elshazly TA, et al. Role of transthoracic CT guided needle aspiration cytology in difficult to diagnose benign and malignant intrathoracic lesions. Egyptian Journal of Bronchology 2013;7(1):4-12.

[21] Herman PG, Hessel SJ. The diagnostic accuracy and complications of closed lung biopsies. Radiology 1977;125(1):11-4.

[22] Hensell DM. Interventional techniques. In: Armstrong P, Wilson AG, Dee P, et al. eds. Imaging of diseases of the chest. $2^{\text {nd }}$ edn. St. Louis: Mosby 1995: p. 894-912.

[23] Bandyopadhyay A, Laha R, Das TK, et al. CT guided fine needle aspiration cytology of thoracic mass lesions: a prospective study of immediate cytological evaluation. Indian J Pathol Microbiol 2007;50(1):51-5.

[24] Singh JP, Garg L, Setia V. Computed tomography (CT) guided transthoracic needle aspiration cytology in difficult thoracic mass lesions not approachable by USG. Indian J Radiol Imaging 2004;14(4):395-400.

[25] Saha A, Kumar K, Choudhari MK. Computed tomography guided fine needle aspiration cytology of thoracic mass lesions: a study of 57 cases. J Cytol 2009;26(2):55-9.

[26] Rawat J, Sindhwani G, Dushyant G, et al. Clinicopathological profile of lung cancer in Uttarakhand. Lung India 2009;26(3):74-6.

[27] Kumar KR, Payal K. Lung Cancer-prevalence and patterns. Mapana Journal of Sciences 2002;1(1).

[28] Krishnamurthy A, Vijayalakshmi R, Gadigi V, et al. The relevance of nonsmoking-associated lung cancer in India: a single-centre experience. Indian J Cancer 2012;49(1):82-8.
[29] Shetty CM, Lakhkhar BN, Gangadhar VSS, et al. Changing pattern of bronchogenic carcinoma: a statistical variation or reality? Ind J Radiol Imag 2005;15(2):233-8.

[30] Al-Rahim YA. Lung cancer in a sample of Iraqi patients. AlKindy Col Med J 2007;4(1):53-9.

[31] Arora VK, Seetharaman ML, Ramkumar S, et al. Bronchogenic carcinoma-clinicopathological pattern in South Indian population. Lung India 1990;7(3):133-8.

[32] Dey A, Biswas D, Saha SK, et al. Comparison study of clinicoradiological profile of primary lung cancer cases: an Eastern India experience. Indian J Cancer 2012;49(1):89-95.

[33] Quamrul M, Ahamad MSU, Rahman MZ, et al. Clinicopathological profile of bronchogenic carcinoma in a tertiary care hospital in Bangladesh. Journal of Chittagong Medical College Teachers Association 2010;21(1):45-9.

[34] Mostafa MG. Computed tomographic guided fine needle aspiration cytology in the diagnosis of thoracic lesions. J Indian Med Assoc 2001;99(10):550-3.

[35] Stanely JH, Fish GD, Andriole JG, et al. Lung lesions: cytological diagnosis by fine needle biopsy. Radiology 1987;162(2):389-91.

[36] Haramati LB. CT-guided automated needle biopsy of the chest. AJR Am J Roentgenol 1995;165(1):53-5.

[37] Mohammad GM. CT guided fine needle aspiration cytology in the diagnosis of thoracic lesions. JIMA 2001;99(10):1-5.

[38] Van Sonnenberg E, Casola G, Ho M, et al. Difficult thoracic lesions: CT-guided biopsy experience in 150 cases. Radiology 1988;167(2):457-61.

[39] Zavala DC, Bedell GN. Transthoracic lung biopsy with a cutting needle. Am Rev Respir Dis 1972;106:186-93.

[40] Zavala DC, Schoell JE. Ultrathin needle aspiration of lung in infectious and malignant disease. Am Rev Respir Dis 1981;123(1):125-31 